\title{
Creació literària
}

\author{
12 POEMAS DE GILDA VÂLCAN \\ (Traducción: Catalina Iliescu)
}

"algo ha sucedido, algo inesperado, algo

que te despoja precisamente ahora y no en otro tiempo

de tu piel de enamorada.

algo gritó en tu cuerpo y el corazón dejó

de latir al ritmo acostumbrado.

el ancla se elevó y flotas a la deriva

en la inmensidad del océano. pero no buscas tierra firme,

¿quizás te diriges hacia otra orilla,

otros lares te llaman cuyo

nombre no sabes aún, o no pronuncias

por miedo a que desaparezca? ¿alguien más te espera?

no, nada ha sucedido,

nadie me espera y no queda ya

ninguna palabra por pronunciar.

la piel de enamorada se fue quitando,

sola, se arrancó de la carne y se secó.

ninguna caricia la alimentó,

ninguna lluvia la envolvió, ninguna palabra

abrazó las arrugas espesas y las heridas mal curadas.

de soledad, de soledad, del eco

nacido en pos de tu llamada, del eco silenciado:

soy joven ahora, soy joven como al principio,

mi nueva piel me cubre y ya no se enamora,

es egoísta como una joven amante, como una fiera indomable,

aunque mi carne envejece y mis huesos,

mis huesos se quiebran bajo el toque del tiempo oculto

en el vientre que lo cría.

voy a parirlo ya viejo, voy a parirlo con muletas

y él admirará, como siempre, mi piel únicamente...

***

dos caminos, dos senderos distintos

entre tú y yo

ni siquiera nos cruzamos,

no sea que nos rocemos

no sea que las miradas se junten 
siquiera de prisa y corriendo, y averigüemos que no nos buscamos, sino que sencillamente andamos a un ritmo ya constante, cada cual con sus altos, con su alambrada para dormir con su sueño bosque bajo un cielo baldío de estrellas, de sol, con hierba quemada, donde ni siquiera de madrugada podemos calmar nuestra sed:

ni rastro de rocío, las lluvias nos han olvidado.

los caminos entre tú y yo

los hemos adoquinado con recuerdos, yo te construía posadas, te plantaba cuentos para mecer tus sueños, me callaba para no darles pistas a los bandoleros, en cada cruce he dejado una larga epístola sobre el día venidero. y tu camino ya no se asemeja a una cárcel, es un simple paseo entre un día y el otro. en mi camino solo encuentro piedras cortantes voces extrañas escupiendo llamaradas de sal incomprensibles, imborrables.

no puedo esquivar las vasijas hechas añicos no tengo en quién apoyarme para quitarme las espinas de los pies. veo que ni siquiera en mente has pasado por aquí, pero sí enviaste emisarios de todo tipo a registrar mis sueños, a escudriñar en mi sangre, en los recuerdos y pensamientos, en busca de un arma, o algo para atravesar mi corazón. pero mi corazón está en el tuyo y tendrás que mondarlo cuidadosamente para llegar hasta el mío.

moriríamos ambos inútilmente sin cruzarnos siquiera, sin que yo pueda ver el abismo de la muerte en tu mirada.

$* * *$

andabas en pos de mí andábamos versificabas mi cuerpo y nunca pronunciabas mi nombre todo era como una quimera que nos lanzábamos el uno al otro 
nada sabía sobre ti

tú tampoco sabías leer

en mis pocos gestos, en mis pocas palabras

exhaladas como plumas livianas,

arriba, hacia el viento.

no era sino cárcel todo

nos recluíamos mutuamente

para ver cómo evade el otro

atravesando qué sueño,

atravesando qué cuento.

siempre teníamos algo que decir

y no decíamos nada: alargábamos el instante

hasta que sus articulaciones cedían al dolor

$\mathrm{y}$, sin embargo,

de hecho,

todo ocurrió por la simple razón

de que eras mucho más bello que yo

nunca me imaginé como parte de la vida

bella de un hombre bello

ansiado por todas las novias.

me parecía que permanecer así, sin deseo alguno,

sin palabra, a tu sombra,

era como si contemplara un ocaso

que pinta mi piel en colores de oro,

aunque lejos, de donde yo soy

el sol no sabe, ni se le pasa por la ensoñación,

que yo pudiera existir.

el sauce murmulla,

mi historia asciende al cielo con el viento.

habría querido que no se lo dijeras a nadie

quedarme encerrada en el reloj de arena

de vez en cuando volverme boca abajo,

yo sola,

contándome mi propia historia sin voz.

habría querido,

pero la caña murmulla. 
llueve en la luna.

no me preguntes

cómo es que sé de la atmósfera

alguien la habrá traído al visitarnos.

no lo recuerdo. no vino nadie por aquí

"desde hace siglos", dices.

desde hace siglos.

la tierra es lejana y siempre crepuscular

mi sitio es el claroscuro a menudo

juego con las partículas de arena.

no, no es el tiempo,

ni es la travesía

tampoco los pequeños desencuentros

y no es ni siquiera la mentira solidificada entre ambos:

el único camino que no presenta riesgos.

no sé andar por él así que floto.

es fácil en la Luna,

solo te cruzas con un risco, con una sombra,

algo que se interpone en tu camino como una pregunta esperada.

amigos ya no somos desde el siglo pasado,

escucho como fluye el viento por tus lares, en la Tierra,

y me doy cuenta de que esperas una palabra.

así que te envío un parpadeo:

ha estado nevando en la Luna hasta hace poco,

ahora llueve y precisamente,

todo ocurre en mi pensamiento...

$* * *$

42.

me abres tus pensamientos con vistas a tu mundo,

no puedo entrar.

las calles amplias y ajenas me dan la calurosa bienvenida.

no me sería difícil tomarlas y dejarme envuelta

en esta caminata.

te abro mis pensamientos con vistas a mi mundo,

no puedes entrar.

las calles...

hombro con hombro miramos cada uno en la dirección del otro.

y toda la ausencia se aúna en mi mirada

y toda la ausencia en la tuya,

y sin embargo no podemos avanzar

las fuentes, y el polvo y el viaje nos esperan.

los libros se leen unos a otros en esta vida. 
vivimos cada uno en el mundo del otro

pero solo con la mirada,

nuestros cuerpos no pueden prometerse nada,

así que hombro con hombro estamos,

y este roce es más que una unión,

y mucho más que una promesa,

es la señal de que moriremos juntos.

$* * *$

aquí es dónde acaba,

aquí donde la tierra cerró tu párpado

sobre tu última palabra y siguió el ocaso.

nadie se inmutó,

comienza el azul atardecer

adelantándose unas sílabas

preparándolos.

la noche no es desierta,

hay una luz viva que transportan

los que estuvieron con nosotros.

no nos despedimos,

no nos miramos.

libramos al otro de su peso

y nos ponemos en marcha, espalda con espalda,

por los caminos

que nunca más se cruzarán

ni siquiera en sueños.

$* * *$

nada tenemos en común,

nada tenemos.

habitas otro universo,

te cobija la sombra de otro verso,

rezas a dioses que ni siquiera he oído nombrar,

amas a veces un muro, una planta, una sombra que te acompaña

hasta que envejece...

nada tenemos en común salvo este amor absurdo

que más bien nos empuja a veces a hacernos daño, cuando nos apetece de repente viajar en el tiempo,

y encontrarnos...

pero no puedo respirar en tu planeta

y tú tampoco en el mío

así que nos juntamos, cada ciertos siglos, durante un microsegundo 
a sabiendas de que nos explotará el cuerpo y la mente y el pensamiento...

y en ese microsegundo nos lanzamos las últimas palabras,

las palabras nuevas,

que hemos de memorizar hasta la próxima vez cuando,

tú llegues y yo te reciba

yo llegue y tú me recibas

así, de algún modo, estaremos siempre juntos

en ese sueño estúpido en el que ambos habitamos un pensamiento.

$* * *$

cerré la puerta en pos de ti y levanté un muro

para evitar la tentación de abrirla.

todos los cuentos que me lees tratan

de los sonidos que se oyen al otro lado de la pared amarillenta.

nos vimos muchas otras veces,

reímos y lanzamos flores,

las lágrimas nos inundaron mil veces,

pero hemos de saber que nosotros, los de ahora

no somos más que héroes imaginarios

salidos de las fotos trucadas de antaño.

$* * *$

te dejo en la línea de flotación y flotas:

no te engulle el abismo,

no vuelas en el profundo cielo,

dejándote llevar por olas esperas con tranquilidad la orilla,

cualquier orilla: que reciba tu cuerpo

relajado por completo

casi desintegrado,

con olor a algas,

siempre lejos de la orilla seca.

pero la orilla te salva una y otra vez,

empaqueta tus sueños sobre ella

y se los vende a los lagos muertos.

de este modo flotas en varios sitios a la vez.

pero no logras encontrarte,

ya no distingues cuál de tus cuerpos es real,

cuál flota en los sueños y cuál

entre el cauce y el abismo.

las aguas son traicioneras,

no puedes preguntarlas,

y el cielo demasiado lejos 
con su susurro.

ya sé que te regaño, ya sé que te voy perdiendo

me cansa perdonarte otra vez,

pero si, si dejara de creer en ti

el mundo perdería la cordura:

nadie tendría ya un nombre,

algunos desplegarían alas inmaculadas

incluso en el instante de apuñalarle el corazón a otro

sé que mi amor ya no significa nada

tras tanto tiempo,

bajo tantos estratos de maquillaje y arrugas.

tampoco ha de significar nada especial

salvo que es bueno que existas allá donde tú creces

y donde te encontraré el día en que te olvide

para asombrarme una vez más

de que existe un sentido, un milagro, una magia

que asegura el equilibrio de toda esta locura

de ser.

tu mundo es de terciopelo.

también lo es el pensamiento y la taza de café,

hasta el reloj que nos escucha

mientras hacemos tic-tac uno dentro del otro...

mi mundo es de barro

y huele totalmente a tierra

como las manos de mi madre y nuestras sábanas

enjuagadas en miles de aguas nuevas.

no hay manera de quitar la tierra de la tierra.

tú eres un muñeco de terciopelo

cosido con hilo de plata.

yo soy una vasija de barro

girada, mareada

entre las manos del alfarero.

en tu mundo las muñecas beben té a horas exactas

en porcelanas finas, cosmopolitas

aquí bebemos agua del arroyo en jarras de barro sin cocer,

para que Dios nos localice más deprisa.

¿Quién sabe cuánto más barro necesita

para crear lo que algún día acabará siendo

un hombre? 
1.

siempre regresabas.

tras algunos siglos en los que lograba olvidarte

$\mathrm{y}$ desear nunca volver a verte.

regresabas.

te sentabas silenciosa, mirándome

con tu amor inamovible,

sin reprocharme nada,

ni el tiempo perdido,

ni los amores intuidos,

ni el silencio con el que te llamaba en sueños.

eras.

como un peñón inquebrantable

por el viento, las lágrimas, el océano

la misma mirada a través de los años

que narraba sobre mí

y sobre todos los habitantes de mí:

cosas y personas que yo

con demasiada ligereza olvidaba.

...

descalza y silenciosa como en los primeros años.

2.

y solo cuando interpretaba mi papel artificial

de niño, de viejo o de truhan,

sonreías permisiva y me contabas,

en el más completo de los silencios,

que cada camino tiene su destino

y ningún ser, ninguna brisa, ninguna mota de polvo,

podrá cambiarlo.

el camino te lleva a dónde quiere,

o a cualquier otro lugar,

allá donde nadie más podrá.

"y tu camino siempre te trae a mí

y no puedo sino

darte la bienvenida un instante.

y en ese instante infinitesimal debo, me obligan,

a despedirme.

Pues no soy más que un cruce de caminos,

aunque juntos formamos una cruz

la tuya llevada en hombros por mi camino, la mía por el tuyo." 